\title{
Surfactant and template free synthesis of porous ZnS nanoparticles
}

DOI:

10.1016/j.matchemphys.2016.12.027

\section{Document Version}

Accepted author manuscript

Link to publication record in Manchester Research Explorer

\section{Citation for published version (APA):}

Akhtar, M. S., Riaz, S., Mehmood, R. F., Ahmad, K. S., Alghamdi, Y. G., Malik, M., \& Naseem, S. (2017).

Surfactant and template free synthesis of porous ZnS nanoparticles. Materials Chemistry and Physics, 189, $28-34$. [1]. https://doi.org/10.1016/j.matchemphys.2016.12.027

\section{Published in:}

Materials Chemistry and Physics

\section{Citing this paper}

Please note that where the full-text provided on Manchester Research Explorer is the Author Accepted Manuscript or Proof version this may differ from the final Published version. If citing, it is advised that you check and use the publisher's definitive version.

\section{General rights}

Copyright and moral rights for the publications made accessible in the Research Explorer are retained by the authors and/or other copyright owners and it is a condition of accessing publications that users recognise and abide by the legal requirements associated with these rights.

\section{Takedown policy}

If you believe that this document breaches copyright please refer to the University of Manchester's Takedown Procedures [http://man.ac.uk/04Y6Bo] or contact uml.scholarlycommunications@manchester.ac.uk providing relevant details, so we can investigate your claim.

\section{OPEN ACCESS}




\section{Accepted Manuscript}

Surfactant and template free synthesis of porous $\mathrm{ZnS}$ nanoparticles

Muhammad Saeed Akhtar, Saira Riaz, Rana Farhat Mehmood, Khuram Shahzad

Ahmad, Yousef Alghamdi, Mohammad Azad Malik, Shahzad Naseem

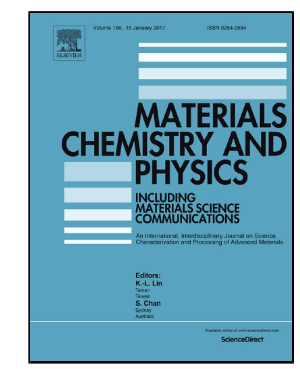

PII:

S0254-0584(16)30926-9

DOI:

10.1016/j.matchemphys.2016.12.027

Reference:

MAC 19358

To appear in:

Materials Chemistry and Physics

Received Date:

16 March 2016

Revised Date:

29 November 2016

Accepted Date:

12 December 2016

Please cite this article as: Muhammad Saeed Akhtar, Saira Riaz, Rana Farhat Mehmood, Khuram Shahzad Ahmad, Yousef Alghamdi, Mohammad Azad Malik, Shahzad Naseem, Surfactant and template free synthesis of porous ZnS nanoparticles, Materials Chemistry and Physics (2016), doi: 10.1016/j.matchemphys.2016.12.027

This is a PDF file of an unedited manuscript that has been accepted for publication. As a service to our customers we are providing this early version of the manuscript. The manuscript will undergo copyediting, typesetting, and review of the resulting proof before it is published in its final form. Please note that during the production process errors may be discovered which could affect the content, and all legal disclaimers that apply to the journal pertain. 


\section{Highlights}

- ZnS thin films composed of porous nanoparticles have been deposited.

- Methodology is based on a combination of three techniques.

- Cubic phase $\mathrm{ZnS}$ nanoparticles deposited onto glass substrates.

- Films characterized by UV/Vis, PL, XRD, SEM, TEM, AFM and XPS 


\section{Surfactant and template free synthesis of porous $\mathrm{ZnS}$ nanoparticles}

Muhammad Saeed Akhtar, ,a,f Saira Riaz, ${ }^{\text {b }}$ Rana Farhat Mehmood, ${ }^{c}$ Khuram Shahzad Ahmad, ${ }^{d}$ Yousef Alghamdi, ${ }^{\mathrm{e}}$ Mohammad Azad Malik, ${ }^{\mathrm{f}, \mathrm{g} *}$ and Shahzad Naseem, ${ }^{\mathrm{b}}$

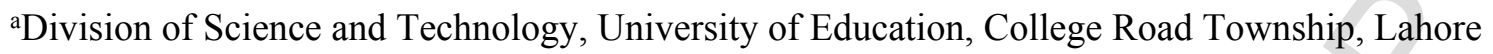
${ }^{\mathrm{b}}$ Centre of Excellence in Solid State Physics, University of the Punjab, Lahore-54590, Pakistan

'University of Education, Lahore, D.G. Khan Campus, Kangan Road, Dera Ghazi Khan, Pakistan

dEnvironmental Sciences Department, Fatima Jinnah Women University, The Mall, Rawalpindi, Pakistan

eDepartment of Chemistry, Faculty of Science \& Art -Rabigh, King Abdulaziz University, Jeddah, Saudi Arabia

fSchools of Materials, The University of Manchester, Oxford Road, Manchester M13 9PL, UK

gDepartment of Chemistry, University of Zululand, Private Bag X1001, Kwa-Dlangezwa, 3886, South Africa

*Corresponding Author

Mohammad Azad Malik

Schools of Materials, The University of Manchester, Oxford Road, Manchester M13 9PL, UK

E-mail: Azad.malik@manchester.ac.uk 


\begin{abstract}
$\mathrm{ZnS}$ thin films composed of porous nanoparticles have been deposited on to glass substrates by combining three simple synthesis methodologies i.e. chemical bath deposition, co-precipitation and spin coating. The XRD results reveal the cubic phase of $\mathrm{ZnS}$ thin films crystallized at nano scale. The crystallite size estimated by Scherrer formula was $3.4 \mathrm{~nm}$. The morphology of the samples was analyzed through scanning electron microscopy (SEM) and is evident that thin films are composed of porous nanoparticles with an average size of $150 \mathrm{~nm}$ and pores of $40 \mathrm{~nm}$ on almost every grain. Crystallinity, phase and morphology were further confirmed via transmission electron microscopy (TEM). The stoichiometry and phase purity of thin films were determined by energy dispersive X-ray (EDX) spectrum and X-ray photoelectron spectroscopy (XPS) analysis, respectively. The surface topography and homogeneity of thin films were analyzed by atomic force microscopy (AFM) and obtained root mean square roughness (4.0326 $\mathrm{nm}$ ) reveals the morphologically homogeneous growth of $\mathrm{ZnS}$ on glass substrates. The UV-Vis spectroscopy and photoluminescence (PL) were carried out to estimate the band gap and observe the emission spectra in order to speculate the viability of $\mathrm{ZnS}$ porous nanoparticles in optoelectronic devices and sensors.
\end{abstract}

Keywords: Thin films, semiconductors, chemical synthesis, precipitation, electron microscopy 


\section{Introduction}

In the recent years, extensive studies have been carried out on the synthesis/deposition and characterization of large band gap semiconductors due to their applications in photovoltaic, photo-electrochemical energy conversion and photoconductors [1, 2]. ZnS is an important II-VI semiconductor with large band gap and have been studied extensively regarding its viability in above mentioned applications. Porous nanoparticles, thin films and structures have attained focus of research since they exhibit novel properties and have many applications in photo-catalytic, luminescent and sensing devices [3-5]. Several methods have been employed to synthesize $\mathrm{ZnS}$ thin films including: chemical spray pyrolysis [6, 7], solvothermal synthesis [8,9], sol-gel [10], successive ionic layer adsorption and reaction (SILAR) [11], pulsed laser deposition (PLD) [12], metal-organic chemical vapor deposition (MOCVD) [13], RF-mganetron sputtering [14, 15], electrodeposition [16, 17], thermal evaporation [18], electron beam evaporation [19], aerosol assisted chemical vapour deposition (AACVD) $[20,21]$ and chemical bath deposition (CBD) [22-30]. Amongst all, CBD is a simple and cost effective method to deposit high quality thin films at relatively low temperatures without need of ultra-high vacuum and sophisticated instrumentation. Synthesis of un-doped and doped $\mathrm{ZnS}$ nanoparticles by various methods has also been reported previously. Most recently, Zhu et al. [31] reported the sonochemical synthesis of mesoporous $\mathrm{ZnS}$ nanocrystals without using template/surfactant. The prepared nanomaterials exhibit higher photo-degradation activity of $\mathrm{Rh}$ under $\mathrm{UV}$ irradiation than that prepared in absence of sonochemistry or in an aqueous system. Pathak et al. [32] reported the synthesis of un-doped and cobalt doped $\mathrm{ZnS}$ nanoparticles by co-precipitation method. However literature suggests that the study and growth of porous $\mathrm{ZnS}$ nanoparticles is lacking. To the best of our knowledge, the deposition of porous $\mathrm{ZnS}$ nanoparticles on glass substrates without use of 
surfactants or templates by any of the chemical technique or combination of them has not been reported yet. However, few reports have been published on study of luminescent properties of ZnS thin films deposited on porous substrates (Si) by different techniques [33].

We have reported the deposition of uniform ZnS thin films by an optimized CBD method [34]. Herein, we report a novel approach to deposit thin films composed of porous $\mathrm{ZnS}$ nanoparticles by simple CBD/co-precipitation and spin coating method. The observed green PL emission of the $\mathrm{ZnS}$ nanoparticles and their porosity are important factors for the development of novel luminescent devices and sensors.

\section{Experimental}

\subsection{Chemicals}

All reagents, zinc chloride, thioacetamide, urea and hydrochloric acid were purchased from Sigma-Aldrich and used without further purification. The de-ionized water was used as solvent. Acetone and isopropyl alcohol (IPA) were used for cleaning of the glass substrate. Glass substrates have already been established as the best substrates to study the optical properties of the thin films as compared to sapphire or $\mathrm{MgF}_{2}$ substrates due to their negligible interaction on the optical properties of the material deposited onto them. Analytical grade ethanol was used for spin coating the films.

\subsection{Instruments}

X-Ray diffraction measurements were performed using Bruker D8 advance Diffractometer with $\mathrm{Cu}-\mathrm{Ka}$ radiation. Data were recorded across a $2 \theta$ range of 20 to $80^{\circ}$ with a step size of $0.05^{\circ}$. SEM and EDX analyses were carried out using Philips XL 30 microscope. TEM, HRTEM and SAED images were collected from Tecnai 20 F30 transmission electron microscope using 
accelerating voltage of $200 \mathrm{kV}$. An atomic force microscope (AFM) PeakForce QNM was used to measure surface roughness of the $\mathrm{ZnS}$ thin films. Absorbance and transmittance spectrum was acquired using Agilent HP 8453 UV-Vis spectrophotometer. Fluorolog 22 HORIBA JOBINYVON was used to obtain photoluminescence data using excitation wavelength of $340 \mathrm{~nm}$.

\subsection{Synthesis of porous $\mathrm{ZnS}$ thin films}

The synthesis of porous $\mathrm{ZnS}$ thin films was carried out in three steps by using $\mathrm{CBD}$, coprecipitation and spin coating, separately.

\subsubsection{CBD/co-precipitation}

Chemical bath deposition/co-precipitation of $\mathrm{ZnS}$ was carried out first. Chemical bath containing zinc chloride $(0.2 \mathrm{M})$, urea $(3 \mathrm{M})$ and thioacetamide $(0.4 \mathrm{M})$ was used to synthesize $\mathrm{ZnS}$. The solutions of zinc chloride $(40 \mathrm{~mL})$, thioacetamide $(40 \mathrm{~mL})$, and urea $(20 \mathrm{~mL})$ were mixed in a beaker to get total volume of $100 \mathrm{~mL}$ bath solution. The $\mathrm{pH}$ of bath solution was adjusted to 4.0 by drop wise addition of $1.0 \mathrm{M} \mathrm{HCl}$. The stirred bath solution was maintained at a temperature of $80{ }^{\circ} \mathrm{C}$. The reaction process for the formation of $\mathrm{ZnS}$ in $\mathrm{CBD}$ is based on, first the slow release of zinc and sulfur ions within the solution followed by condensation of these ions [30]. Balance between hydrolysis and condensation can be adjusted by the presence of urea in the solution [35]. Conventionally, in $\mathrm{CBD}$, the deposition of thin films would be carried out under uniform magnetic stirring to avoid precipitation throughout the reaction time. After the deposition of thin films, the reaction mixture is usually disposed. In the present experiment, the mixture was stirred for 3 hours at $80{ }^{\circ} \mathrm{C}$ and then the stirring was stopped while the mixture was further heated for $1 \mathrm{hr}$. The heating was stopped and the white precipitate formed was 
centrifuged and washed three times with methanol to remove the byproducts of reaction. The precipitate was then dried under vacuum at room temperature and kept under nitrogen. The powder obtained after drying was then used to deposit the thin films of $\mathrm{ZnS}$ on glass substrates by spin coating.

\subsubsection{Spin coating of $\mathrm{ZnS}$ thin films}

The dried powder was aged at room temperature under nitrogen stream for 24 hours to avoid oxidation. For spin coating, powder samples were dispersed in ethanol and were deposited on pre-cleaned glass substrates. The solution was spun at $500 \mathrm{rpm}$ for first $5 \mathrm{sec}$. and then at 3000 rpm for further $25 \mathrm{sec}$. in order to achieve uniform coating of material onto the substrates. Three subsequent layers were deposited to achieve workable thickness of the samples. After deposition, all the samples were annealed under nitrogen atmosphere for one hour in tube furnace at $400{ }^{\circ} \mathrm{C}$ to remove any volatile by-products and improve the crystallinity before further characterization.

\section{Results and Discussion}

\subsection{Structural studies}

Figure 1 shows the typical X-ray diffraction pattern of $\mathrm{ZnS}$ films. The diffraction peaks are intense and broad, suggesting the formation of crystallites with size in the nano regime. The major peaks of pure $\mathrm{ZnS}$ are observed. Three broad peaks corresponding to the (111), (220) and (311) lattice planes are well matched with reported data (ICSD \# 01-080-0020) and can be assigned to the cubic phase of $\mathrm{ZnS}$. The vertical lines on $\mathrm{x}$-axis represent the standard pattern of cubic $\mathrm{ZnS}$. The XRD pattern shows that the thin films are single phase since there is no diffraction peak regarding any impurity or other (hexagonal) phase of ZnS. A small but bit broader peak (hump) observed between the $2 \theta$ values of $20-25^{\circ}$ is due to glass substrate. 


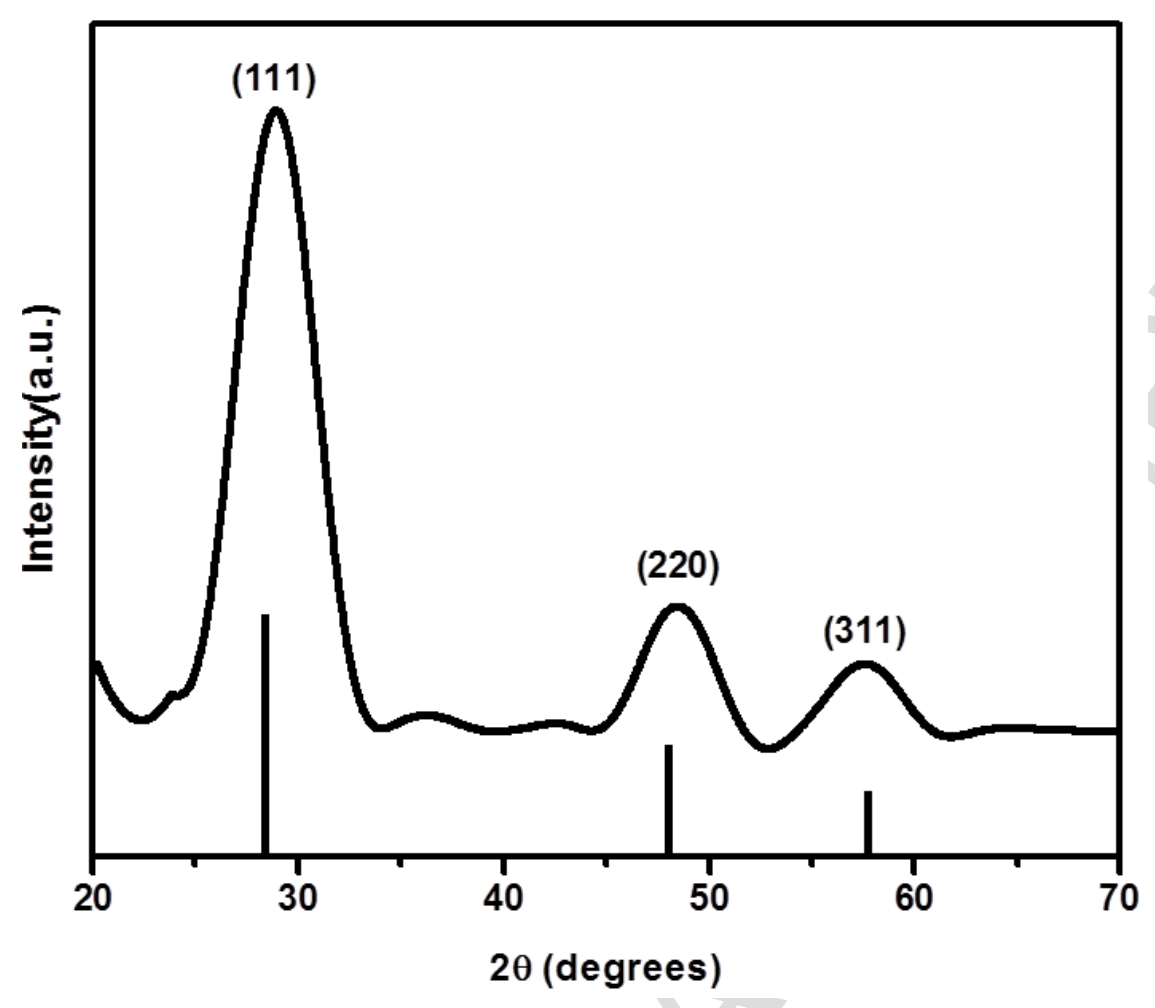

Fig. 1: XRD pattern of ZnS thin film

From the full width at half maximum (FWHM) of most intense peak (111), the average crystallite size was estimated by Scherrer's equation as; $D=0.9 \lambda / \beta \cos \theta$, where $D$ is the crystallite size, $\lambda$ is the $\mathrm{X}$-ray wavelength of $\mathrm{Cu}-\mathrm{K} \alpha$ radiations $(1.5405 \AA), \beta$ is the full width at half maximum (in radian), and $\theta$ is the Bragg diffraction angle. The calculated crystallite size was 3.4 nm. Cell parameters calculated by the relation; $a=d\left(\sqrt{h^{2}+k^{2}+l^{2}}\right)$ and found as $a=b=c=$ $5.32 \AA$, which are close enough to the reported values of lattice constants in ICSD \# 01-080-0020. The dislocation density $(\delta)$, defined as the length of dislocation lines per unit volume was estimated using the equation [36]; $\delta=\frac{1}{\mathrm{D}^{2}}$ and obtained as $0.0865 \mathrm{~nm}^{-2}$. Lattice strain $(\varepsilon)$ in the thin film was estimated using the equation [37]; $\varepsilon=\frac{B \operatorname{Cos} \theta}{4}$ and obtained a value of -0.193 showing that the material was deposited with least value of strain in the lattice. 


\subsection{Morphology and Stoichiometry}

The SEM micrographs at different magnifications for the $\mathrm{ZnS}$ thin film are shown in Figure 2. Images at high magnifications (Figure $2(\mathrm{a}-\mathrm{b})$ ) reveal that films are composed of porous nanoparticles. Low magnification image (Figure 2c) reveals that deposit is in the form of almost spherical agglomerates of particles with their size in nanometer range and is deposited uniformly throughout the substrate surface (Figure 2d). The apparent size of most of the particles is less than $200 \mathrm{~nm}$ and the size of pores on almost every grain is $40 \mathrm{~nm}$ (Figure 2a). Thin films of $\mathrm{ZnS}$ obtained using same materials by CBD on glass substrate show non-porous and almost spherical nanoparticles [34].
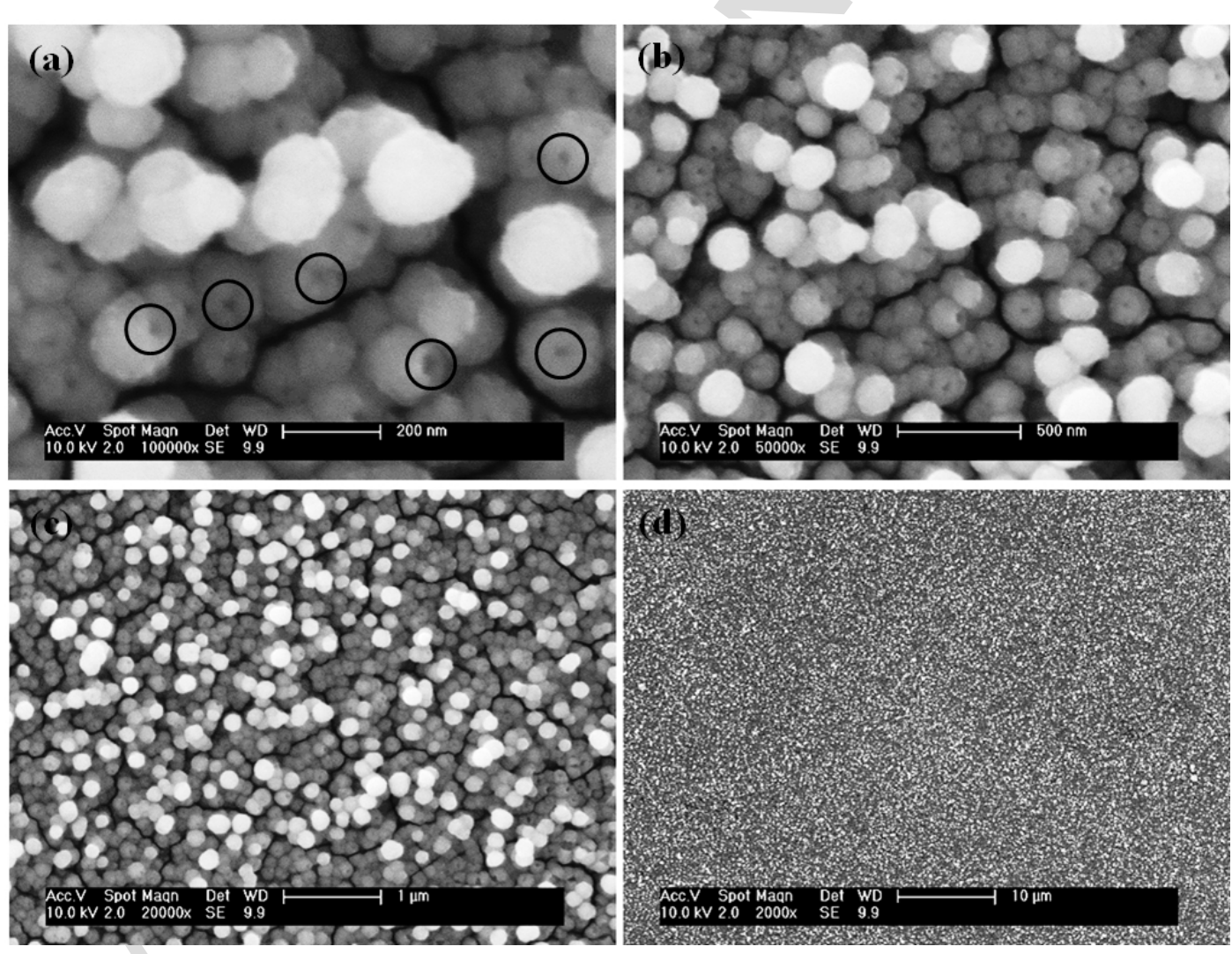

Fig. 2: SEM micrographs (at various magnifications) of spin coated porous $\mathrm{ZnS}$ thin film 
The spin coating of the residue from CBD might have the major role in obtaining the porous nanoparticles. To validate this argument, SEM analysis of nanoparticles before spin coating was also performed and found that nanoparticles exhibit almost spherical morphology as obtained after spin coating but without porous structure (Figure 3). For that reason, this observation needs further studies to elaborate the in-situ mechanism of spin coated $\mathrm{ZnS}$ thin films comprised of porous nanoparticles. Figure 4 shows the particle size distribution in spin coated $\mathrm{ZnS}$ thin film evaluated by ImageJ tool. The majority of particles have their size distribution in the range from $120-180 \mathrm{~nm}$.

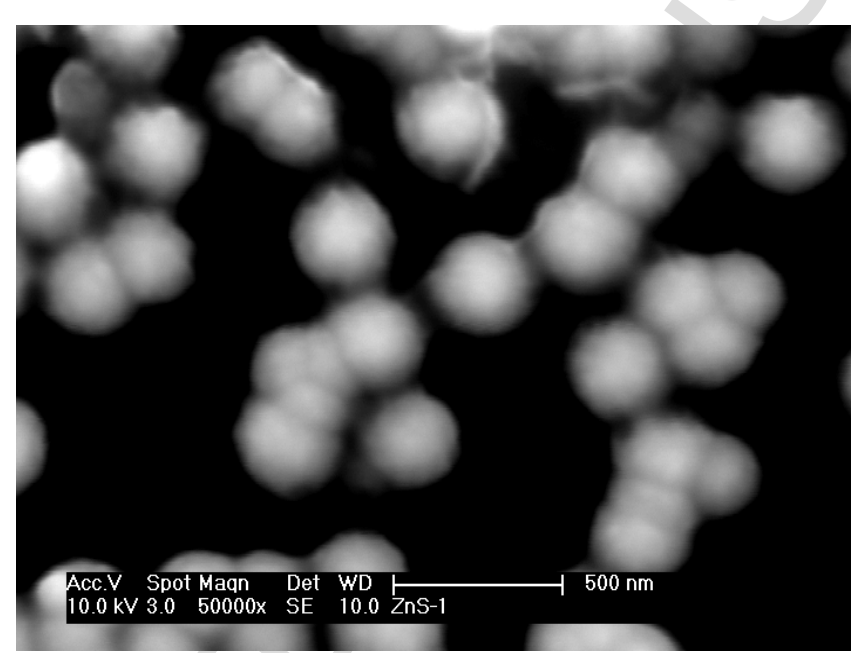

Fig. 3: SEM micrograph of $\mathrm{ZnS}$ nanoparticles before spin coating

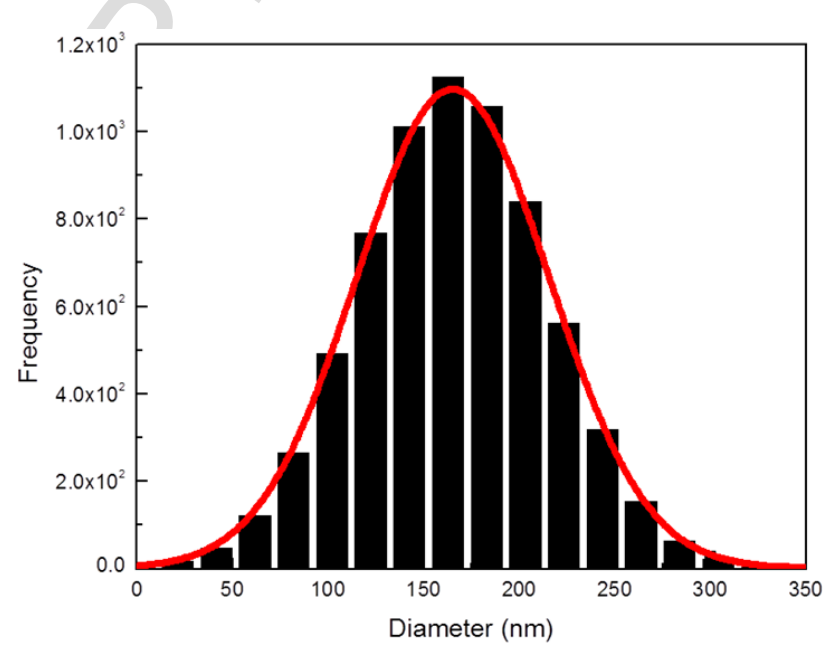

Fig. 4: particle size distribution of porous $\mathrm{ZnS}$ thin film 
Stoichiometry of the elemental composition of ZnS thin films was analyzed through EDX which confirmed that the deposited thin films have $\mathrm{Zn:S}$ ratio of $\sim 1: 1$ Glass constituents such as, silicon, sodium, calcium, magnesium, potassium and aluminum were also detected in EDX spectrum because of the thin nature of the films. Figure 5 shows the EDX pattern of $\mathrm{ZnS}$ thin films on glass substrates.

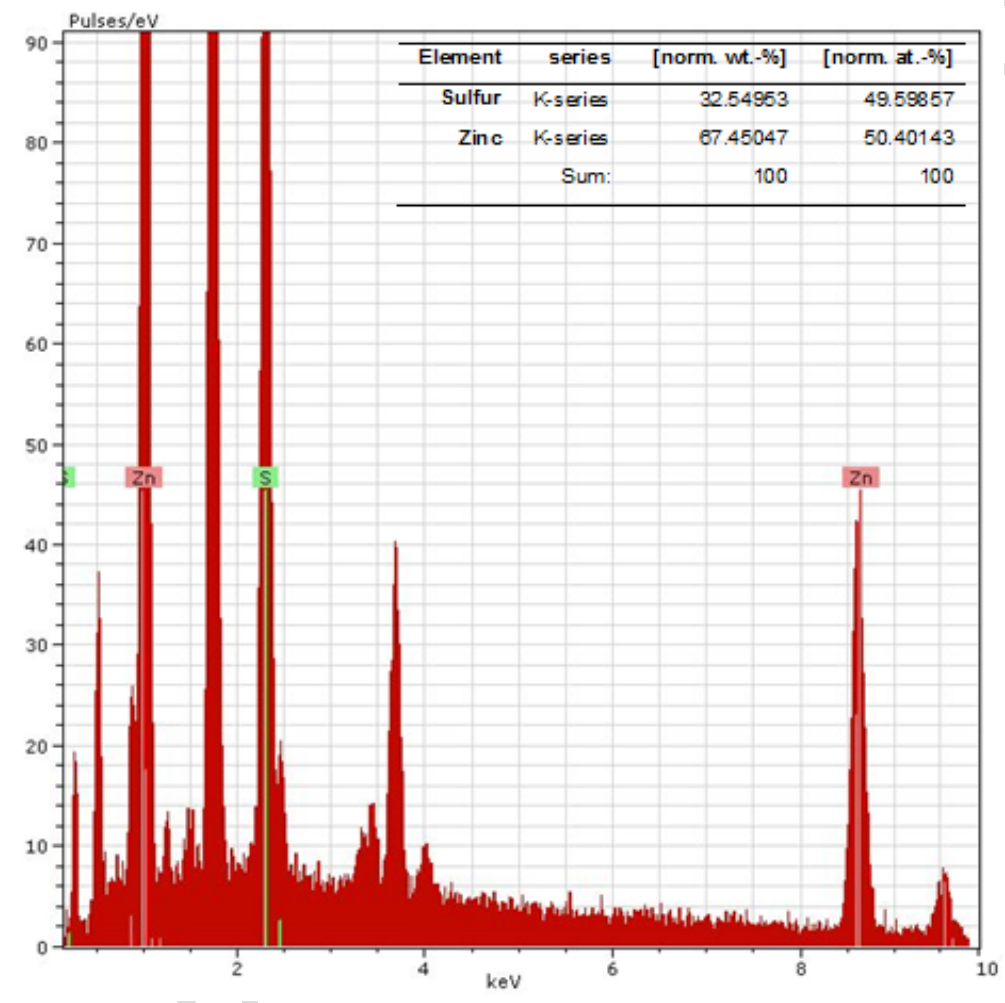

Fig. 5: EDX pattern of ZnS thin films

To support the evidence of $\mathrm{ZnS}$ deposition on glass substrate by EDX, X-ray photoelectron spectroscopy was carried out for thin films. Besides the wide scan spectrum in the range of 0$1200 \mathrm{eV}$, detailed spectra for the $\mathrm{Zn}_{2 \mathrm{p}}$ and $\mathrm{S}_{2 \mathrm{p}}$ regions were obtained and presented in Figure 6. The black and red lines represent the obtained and fitted data, respectively. The XPS spectra of $\mathrm{ZnS}$ thin film reveal the formation of stoichiometric and impurity free zinc sulfide. The binding 
energies of zinc and sulfur corresponding to their $2 p$ orbitals observed at 1019 and $160 \mathrm{eV}$ respectively. A small shift in binding energies can be attributed to the chemical effects along with matrix effects i.e. relaxation energy, work function and crystal potential [38].
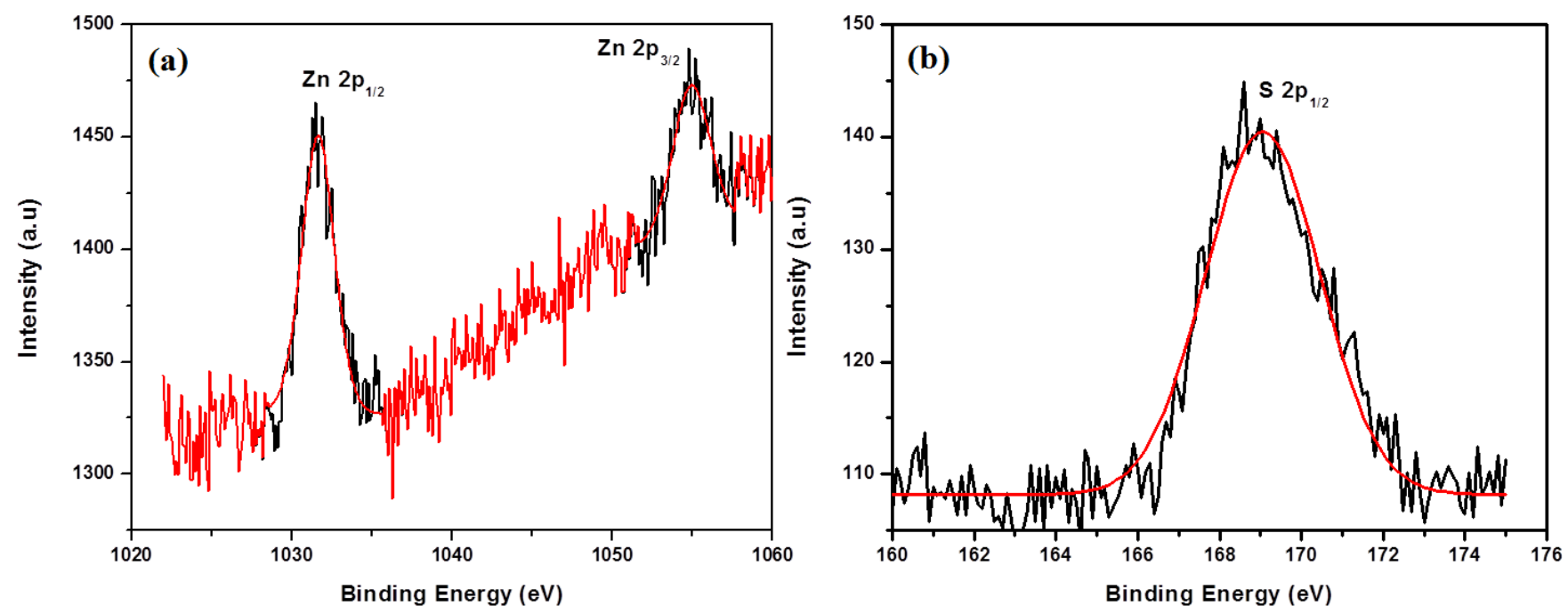

Fig. 6: XPS spectra of ZnS thin films deposited by CBD method

The morphology of the deposited porous $\mathrm{ZnS}$ nanoparticles was further investigated by transmission electron microscopy. Figure 7 shows the representative transmission electron microscopy (TEM), high resolution transmission electron microscopy (HRTEM) images and selected area electron diffaraction (SAED) pattern of ZnS nanoparticles. The TEM observations show that it is dificult to observe the actual size of nanoparticles due to aggregation of particles as seen in the Figure 7 (a). The small crystallite aggregate into secondary nanoparticles since they have extremely small dimensions with higher surface energy due to high surface-to-volume ratio. The observation of monodisperesed nanoparticles in TEM samples may be possible by diluting and sonicating the samples for a long time.. HRTEM image (Figure 7b) shows that $\mathrm{ZnS}$ nanoparticles are of good crystallinity. Figure $7(\mathrm{~d}, \mathrm{e})$ shows lattice spacing as $0.30 \mathrm{~nm}$ corresponding to (111) plane of cubic phase consistent with the results obtained from XRD 
analysis. Figure 7 (c) shows the SAED pattern which is analogous to the cubic zinc blende structure of $\mathrm{ZnS}$ as investegated by XRD. Polycrystalline nature of $\mathrm{ZnS}$ nanoparticles was confirmed by appearance of wide diffraction rings made up of many diffraction spots. The diffraction rings in SAED pattern coreespond to (111), (220) and (311) planes of cubic phase of $\mathrm{ZnS}$. The electron diffaction reveals that each grain is composed of many crystallites with extremely small nuclei.

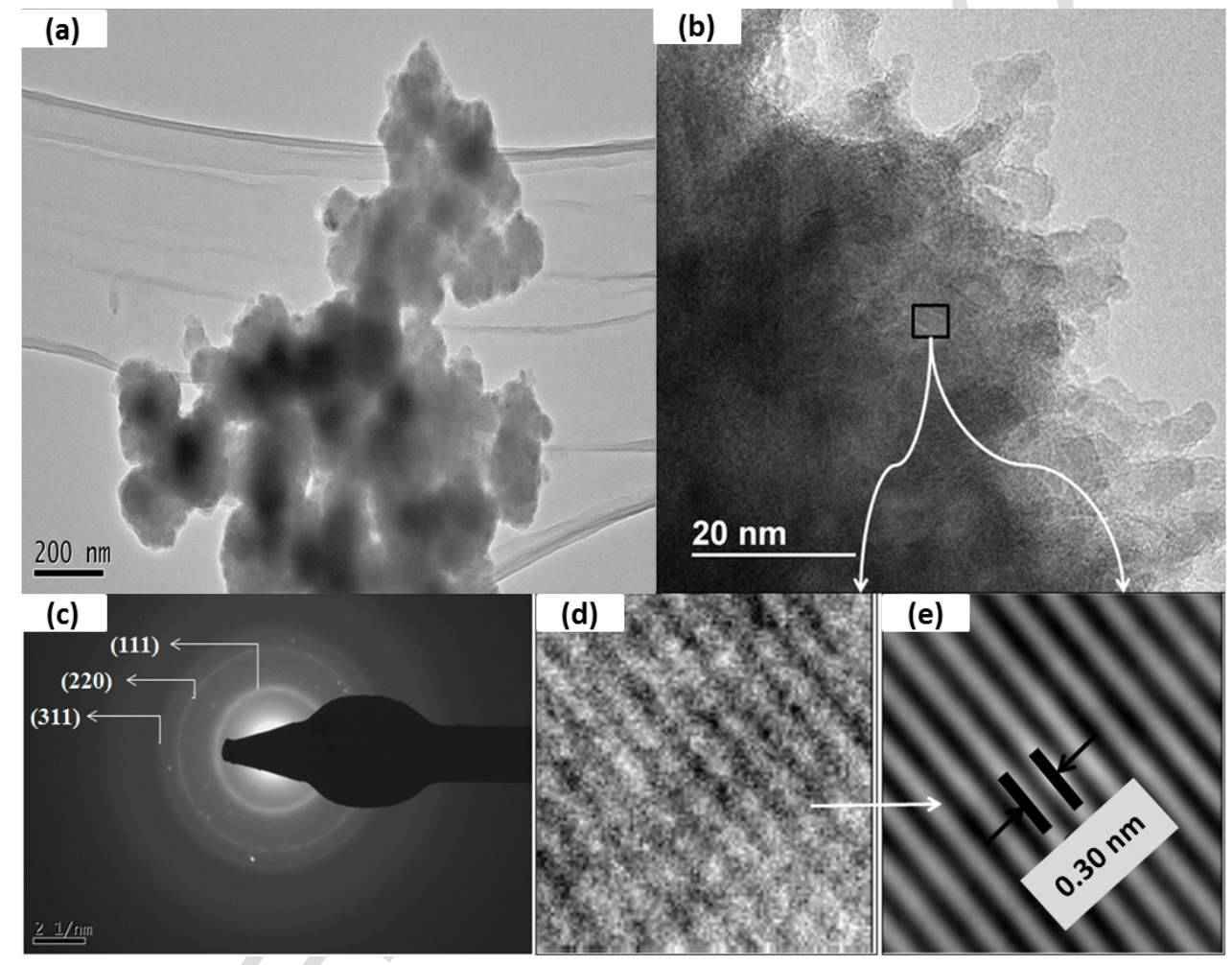

Fig. 7: TEM, HRTEM and SAED images ZnS porous nanoparticles

The surface topography images were obtained from Atomic Force Microscope (AFM) used as a source of information about the root mean square roughness, height of the deposited layer and the size of particular features as grains or pores. Figures 8 and 9 show the AFM data collected for $\mathrm{ZnS}$ thin films in non-contact mode. From the 2D/topography image and contour plot of topography (Figure $8(\mathrm{a}, \mathrm{b})$ ), it can be observed that grains are uniformly distributed throughout 
the substrate surface. 3D image (Figure 8c) of the sample also reveals the distribution of grains and surface morphology. Figure 9 shows the grain size estimation (line profile), topography for root mean square roughness (RMS) and bearing surface/volume plots for CBD deposited ZnS thin films.

In order to determine the appropriate relation between the synthesis methodology and morphology of the surface, the size, shape, orientation and density of grains is very important. Figure 9 (a) shows the line profile to estimate the average grain size $\sim 200 \mathrm{~nm}$. The shape and density of these grains along with thickness of the film $(\sim 400 \mathrm{~nm})$ are in agreement to the SEM micrographs. The surface profile of the films was used to obtain probability density function as Bearing Area Curve (BAC) and Bearing Volume Curve (BVC) shown in Figure 9 (c, d). The root mean square roughness $(4.0326 \mathrm{~nm})$ reveals the morphologically homogeneous growth of $\mathrm{ZnS}$.

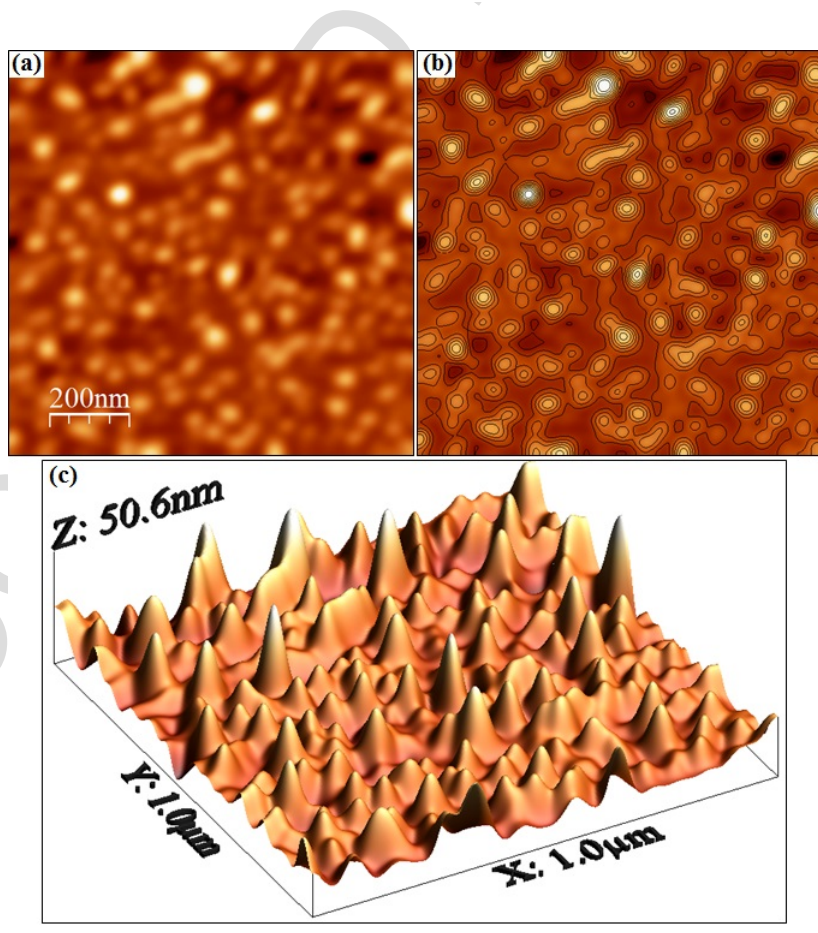

Fig. 8: AFM images (a) 2D topography, (b) contour plot and (c) 3D surface topography of CBD deposited $\mathrm{ZnS}$ thin film 

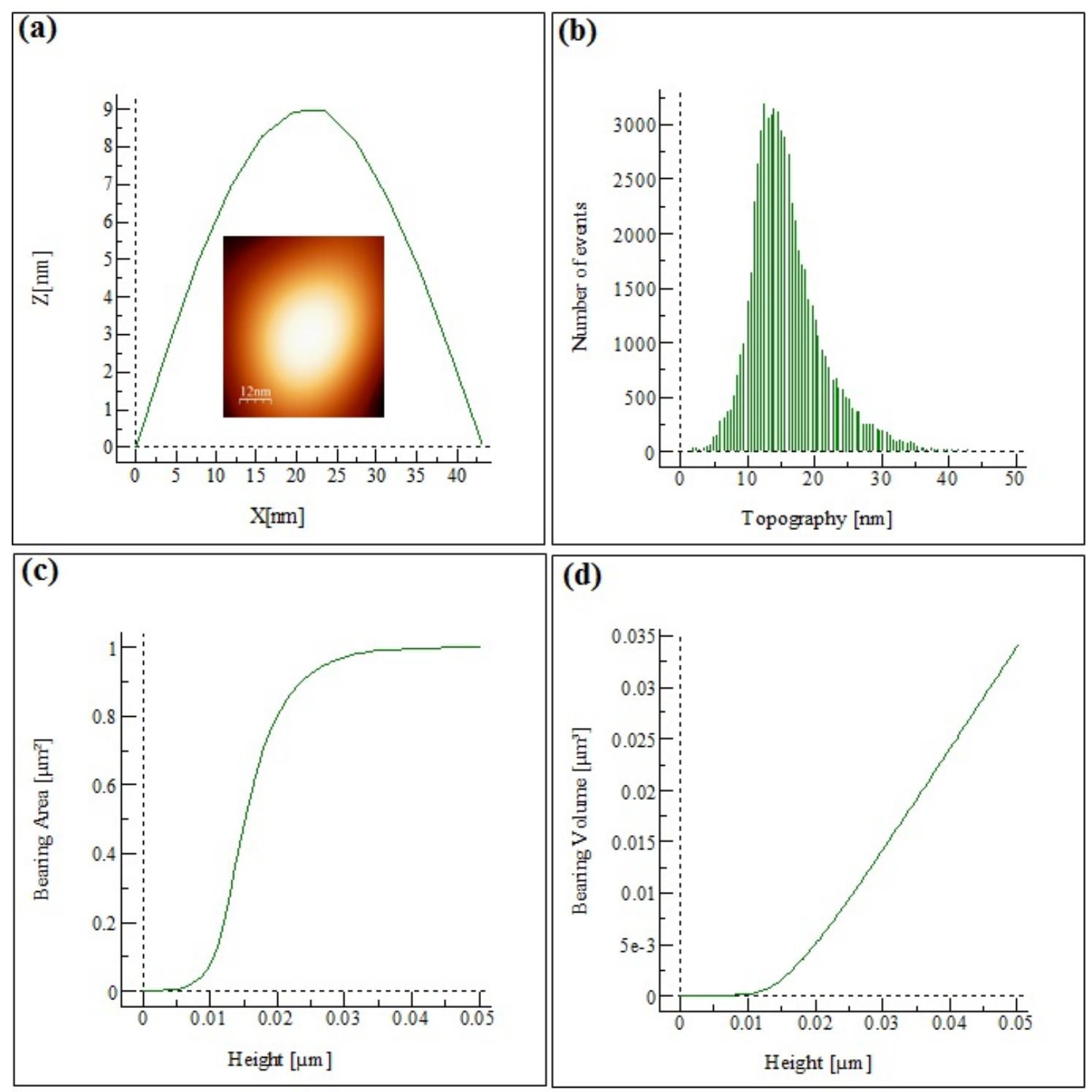

Fig. 9: AFM data analysis images, (a) grain size estimation, (b) topography for RMS and (c, d) bearing surface and volume plots for CBD deposited $\mathrm{ZnS}$ thin film

\subsection{Optical studies}

The absorbance of $\mathrm{ZnS}$ thin films was obtained from UV-Vis spectrometer. The transmittance and absorbance plots (figure 10) show 75-95\% transmittance in the major portion of visible region and almost $100 \%$ transmission in infrared region of the solar spectrum. The high transparency of deposited $\mathrm{ZnS}$ thin films would have applications in optoelectronic devices. 


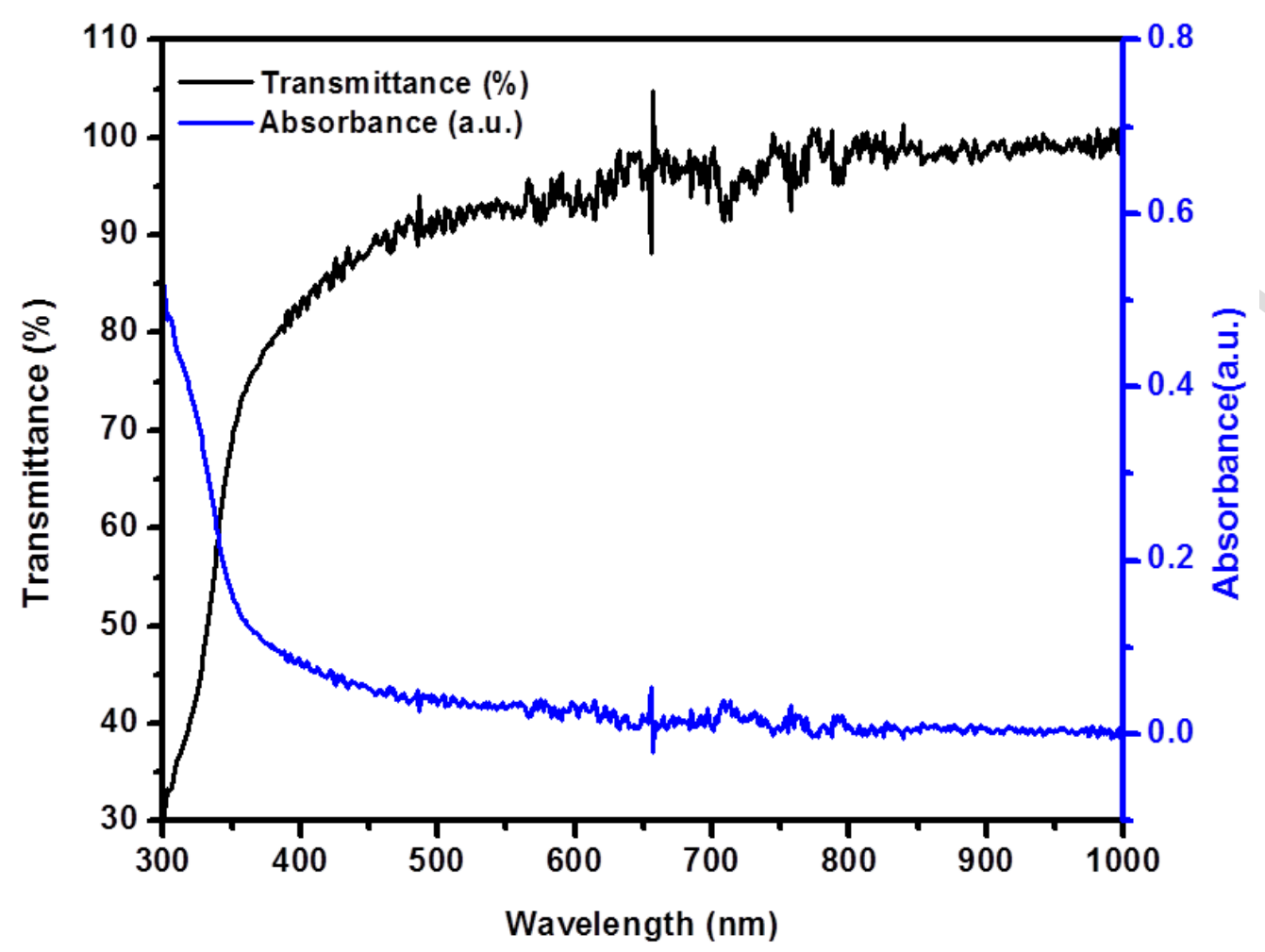

Fig. 10: Absorbance and Transmittance of CBD deposited $\mathrm{ZnS}$ thin films

Absorption co-efficient was calculated and is related to the optical band gap by the relation $\boldsymbol{\alpha}=$ $\left(\frac{\boldsymbol{k}}{\boldsymbol{h} \boldsymbol{v}}\right)\left(\boldsymbol{h} \boldsymbol{v}-\boldsymbol{E}_{\boldsymbol{g}}\right)^{\boldsymbol{n}}$, Where $\mathrm{k}$ is a constant, h is Planck's constant, hv is the incident photon energy and $\mathrm{n}$ is a number which characterizes the nature of electronic transitions between valance and conduction bands [39]. For direct allowed transitions $n=1 / 2$ and it is known that $\mathrm{ZnS}$ is a direct band gap semiconductor. Therefore the formula used is $\left(\frac{\mathrm{k}}{\mathrm{hv}}\right)\left(\mathrm{hv}-\mathrm{E}_{\mathrm{g}}\right)^{\frac{1}{2}}$.

Figure 11 shows the variation of $(\alpha h v)^{2}$ with photon energy hv. The deposited material exhibit direct type of transition as observed from the linear portion of $(\alpha h v)^{2} \mathrm{Vs} h v$ curve over a wide range of photon energies. The linear portion of the curve was extrapolated to evaluate the energy gap Eg of the $\mathrm{ZnS}$ thin films. The intercept on energy-axis estimates the band gap energy (3.70 $\mathrm{eV})$ bit higher than that of bulk cubic $\mathrm{ZnS}(3.54 \mathrm{eV})[40]$ due to nanocrystalline nature of thin films [41]. Optical results are completely in co-relation with the XRD analysis since few of the reports determined the hexagonal phase $[42,43]$ of $\mathrm{ZnS}$ by CBD method. 


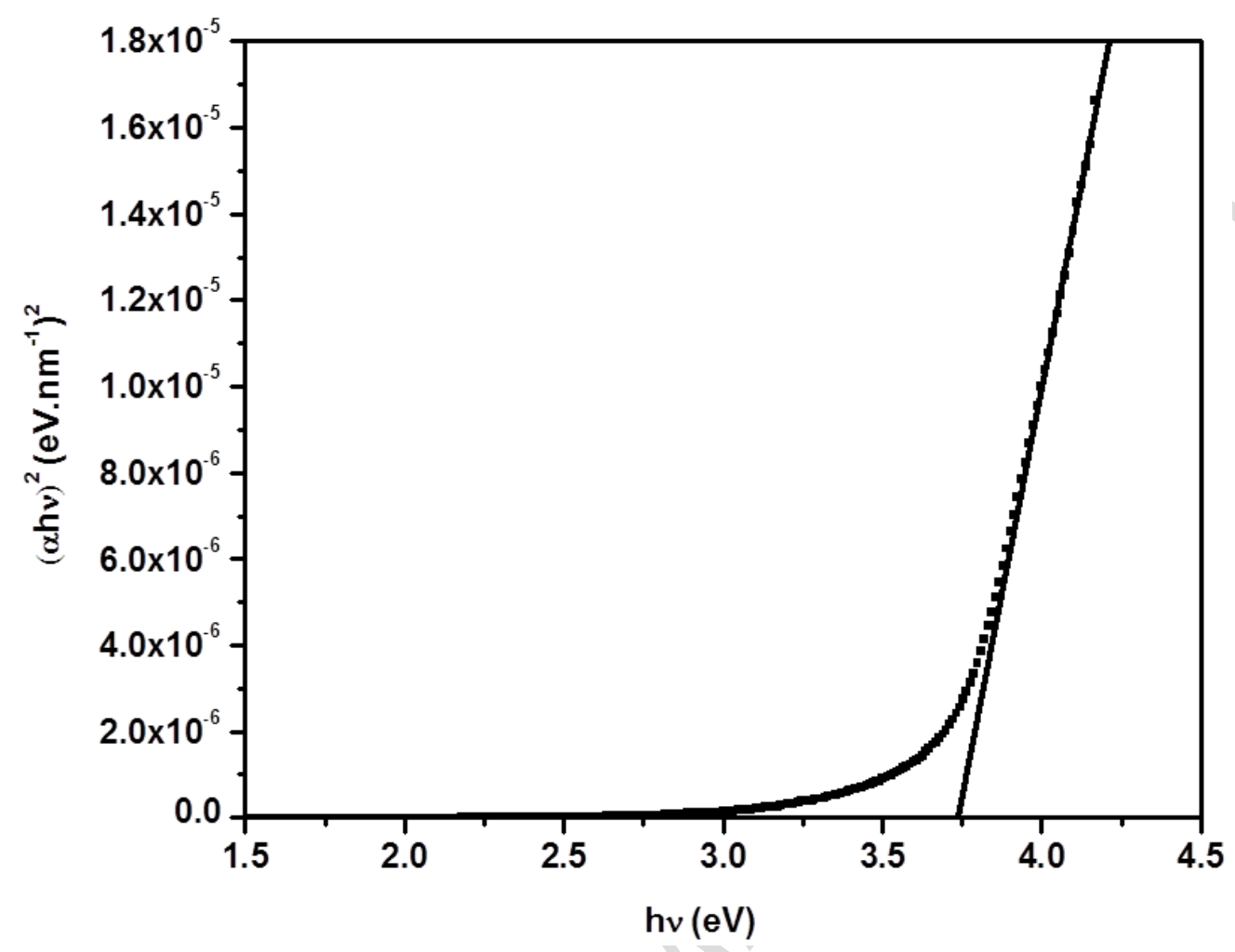

Fig. 11: Band gap plot of $\mathrm{ZnS}$ thin film

The photoluminescence spectra for $\mathrm{ZnS}$ thin films were carried out at room temperature with an excitation wavelength of $340 \mathrm{~nm}$. Emission spectrum of the nano porous $\mathrm{ZnS}$ thin film is shown in Figure 12. Multi-peak Gaussian fitting gives two bands one at $396 \mathrm{~nm}$ and the second at 507 $\mathrm{nm}$. The emission peak at $396 \mathrm{~nm}$ is related to the sulfur vacancies at the surface of the sample as observed previously [44]. The broad emission band at $507 \mathrm{~nm}$ is might be attributed to the electron recombination from sulfur vacancies to the surface defects of $\mathrm{ZnS}$ nanoparticles [45]. It is obvious that, growth of thin films composed of nanoparticles with different sizes extensively affect the photoluminescence of the material. The variation in optical properties strongly depends on the existence and density of defects incorporated in the thin films which act as photo-excited carriers and centers of radioactive recombination $[46,47]$ 


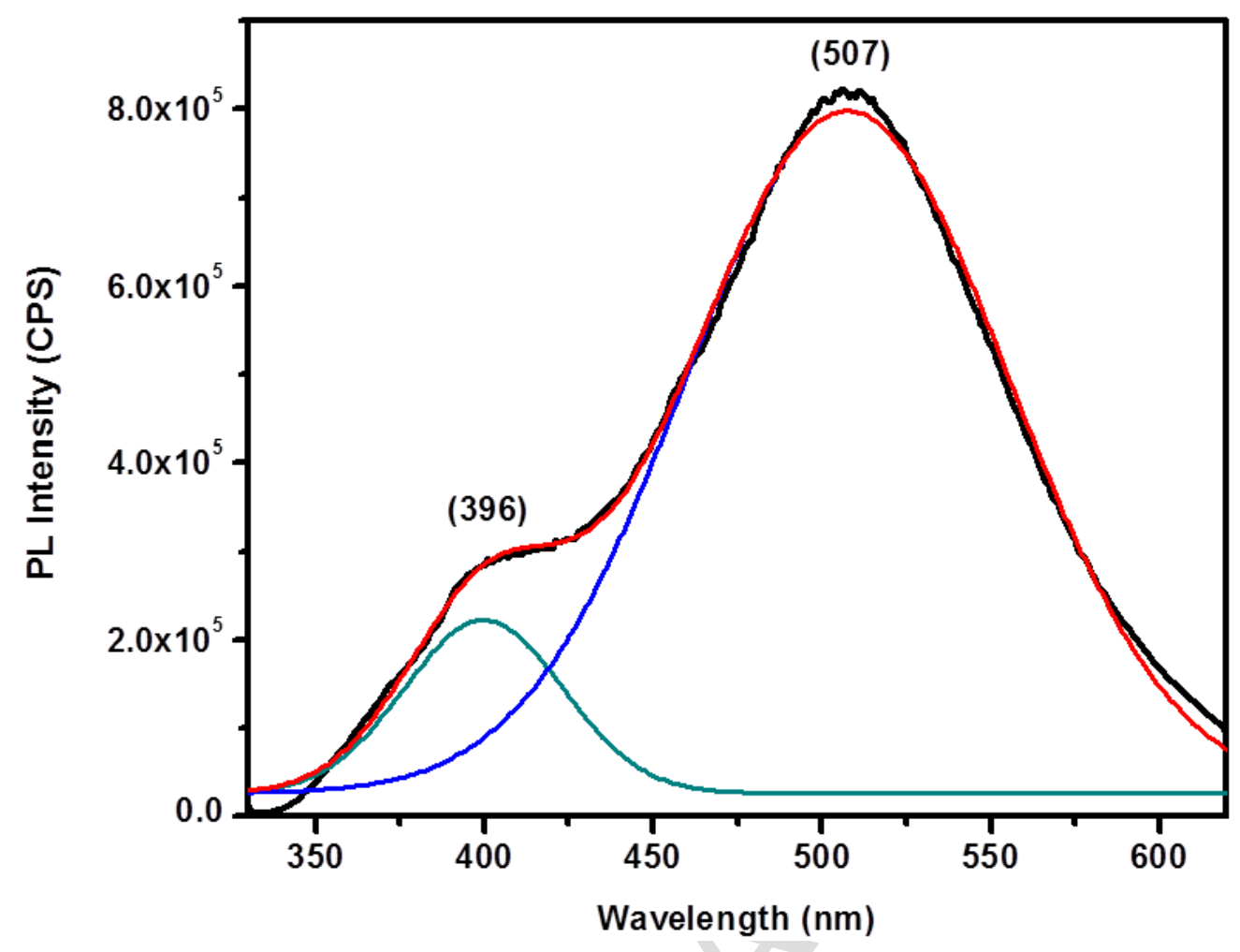

Fig. 12: $\mathrm{PL}$ of deposited $\mathrm{ZnS}$ thin film

The observed luminescent intensity in the present study is many fold higher than that observed earlier by Yang et al. [5] in addition to the emission of photons with comparable energy. The porous structure of $\mathrm{ZnS}$ nanoparticles could improve intensity of luminescence due toits greater surface area and the fact that existence of pores would enhance the absorption of light. Porous structures also boost the recombination of photo-excited carriers through surface vacancies [48]. The argument presented regarding improvement in properties of materials owing to their porous structure is in strong agreement with the observations reported by Yang et al. [49] and An et al. [50] for $\mathrm{ZnS}$ and $\mathrm{ZnO}$, respectively. 


\section{Conclusions}

$\mathrm{ZnS}$ thin film composed of porous nanoparticles has been successfully deposited onto glass substrate via spin coating by using $\mathrm{ZnS}$ precipitates, as starting material, collected from $\mathrm{CBD} / \mathrm{co}-$ precipitation method. The XRD reveals that thin films are nanocrystalline and monophasic with cubic zinc blende phase. Morphological analysis via SEM confirms the depositions of porous nanoparticles with pore diameter of $40 \mathrm{~nm}$. The stoichiometric analyses (EDX, XPS) reveal the deposition of impurity free $\mathrm{ZnS}$ thin films having stoichiometric ratios of constituents as expected. The UV-Vis results are consistent with the XRD data presenting the deposition of $\mathrm{ZnS}$ thin films composed of nanoparticles. In conclusion, nano porous $\mathrm{ZnS}$ thin films synthesized by novel three step methodology showed high crystallinity and have potential applications in advanced optoelectronic devices.

\section{Acknowledgement}

One of the authors (M. Saeed Akhtar) would like to acknowledge the Higher Education Commission (HEC) of Pakistan for providing financial support as IRSIP scholarship (Grant no. 1-8/HEC/HRD/ 2013/2503).

\section{References}

1. Mann, J., et al., Reflection Optimization for Alternative Thin-Film Photovoltaics. leee Journal of Photovoltaics, 2013. 3(1): p. 472-475.

2. Ramli, H., et al., Optimization of Zinc Sulfide (Zns) Electron Affinity in Copper Indium Sulfide (Cis) Based Photovoltaic Cell. Chalcogenide Letters, 2013. 10(6): p. 189-195.

3. Jian, Y., et al., Mesoporous zinc-blende ZnS nanoparticles: synthesis, characterization and superior photocatalytic properties. Nanotechnology, 2008. 19(25): p. 255603.

4. Wang, C.F., et al., The effect of PS porosity on the structure, optical and electrical properties of ZnS/PS. Optics and Spectroscopy, 2014. 116(3): p. 427-430.

5. Yang, C., G. An, and X. Zhao, ZnS porous fluorescent nanostructures synthesized by a soft template approach. Journal of Materials Science: Materials in Electronics, 2015. 26(5): p. 33243329. 
6. Safeera, T.A., et al., Synthesis And Characterization Of Nanostructured ZnS Thin Film. Solid State Physics, Vol 57, 2013. 1512: p. 668-669.

7. Zeng, X., et al., Low temperature synthesis of wurtzite zinc sulfide (ZnS) thin films by chemical spray pyrolysis. Physical Chemistry Chemical Physics, 2013. 15(18): p. 6763-6768.

8. Wang, X.M., et al., Solvothermal Synthesis of Superhydrophobic ZnS Film. Asian Journal of Chemistry, 2013. 25(3): p. 1241-1243.

9. Zhang, Y.D. and L.W. Mi, In Situ Fabrication of Superhydrophobic Zinc Sulfide Films on a Flexible Zinc Foil Substrate. Chemistry Letters, 2012. 41(9): p. 915-916.

10. Turgut, G., et al., A study on characterization of Al/ZnS/p-Si/Al heterojunction diode synthesized by sol-gel technique. Materials Letters, 2013. 102: p. 106-108.

11. Fischereder, A., et al., Mesoporous ZnS Thin Films Prepared by a Nanocasting Route. Chemistry of Materials, 2012. 24(10): p. 1837-1845.

12. Zhang, W., et al., Phase controlled synthesis and optical properties of ZnS thin films by pulsed laser deposition. Materials Research Bulletin, 2013. 48(10): p. 3843-3846.

13. Yoon, Y.G. and I.H. Choi, Preparation of ZnS thin films by using photoassisted MOCVD. Journal of the Korean Physical Society, 2013. 63(8): p. 1609-1614.

14. Yoo, D., et al., Structural, optical and chemical analysis of zinc sulfide thin film deposited by RFmganetron sputtering and post deposition annealing. Metals and Materials International, 2013. 19(6): p. 1309-1316.

15. Yoo, D., et al., Characteristics of Radio Frequency-Sputtered ZnS on the Flexible Polyethylene Terephthalate (PET) Substrate. Journal of Nanoscience and Nanotechnology, 2013. 13(12): p. 7814-7819.

16. Xu, X.H., et al., Effect of sulfosalicylic acid (C7H6O6S) on the electrodeposition of pure ZnS nanocrystal thin films from acidic solutions. Electrochimica Acta, 2013. 87: p. 511-517.

17. Hennayaka, H.M.M.N. and H.S. Lee, Structural and optical properties of ZnS thin film grown by pulsed electrodeposition. Thin Solid Films, 2013. 548: p. 86-90.

18. Zhou, M., et al., The optical properties of different temperature deposited ZnS film in visible to near-infrared region. 6th International Symposium on Advanced Optical Manufacturing and Testing Technologies: Optoelectronic Materials and Devices for Sensing, Imaging, and Solar Energy, 2012. 8419.

19. Abdullah, H. and S. Habibi, Effect of Annealing Temperature on CulnSe2/ZnS Thin-Film Solar Cells Fabricated by Using Electron Beam Evaporation. International Journal of Photoenergy, 2013.

20. Ehsan, M.A., et al., Surface morphological and photoelectrochemical studies of ZnS thin films developed from single source precursors by aerosol assisted chemical vapour deposition. Thin Solid Films, 2013. 540: p. 1-9.

21. Ramasamy, K., et al., Thio- and Dithio-Biuret Precursors for Zinc Sulfide, Cadmium Sulfide, and Zinc Cadmium Sulfide Thin Films. Chemistry of Materials, 2011. 23(6): p. 1471-1481.

22. Agawane, G.L., et al., Green route fast synthesis and characterization of chemical bath deposited nanocrystalline ZnS buffer layers. Current Applied Physics, 2013. 13(5): p. 850-856.

23. Zhong, Z.Y., E.S. Cho, and S.J. Kwon, Characterization of the ZnS thin film buffer layer for Cu(In, Ga)Se-2 solar cells deposited by chemical bath deposition process with different solution concentrations. Materials Chemistry and Physics, 2012. 135(2-3): p. 287-292.

24. Iwashita, T. and S. Ando, Preparation and characterization of ZnS thin films by the chemical bath deposition method. Thin Solid Films, 2012. 520(24): p. 7076-7082.

25. Bhaskar, P.U., et al., Effect of bath concentration, temperature on the growth and properties of chemical bath deposited ZnS films. Materials Chemistry and Physics, 2012. 134(2-3): p. 11061112. 
26. Agawane, G.L., et al., Non-toxic complexing agent Tri-sodium citrate's effect on chemical bath deposited ZnS thin films and its growth mechanism. Journal of Alloys and Compounds, 2012. 535: p. 53-61.

27. McAleese, J. and P. O'Brien, Nucleation studies of ZnS and ZnO growth by Chemical Bath Deposition (CBD) on the surface of glass and tin oxide coated glass. Thin-Film Structures for Photovoltaics, 1998. 485: p. 255-260.

28. Oladeji, I.O. and L. Chow, A study of the effects of ammonium salts on chemical bath deposited zinc sulfide thin films. Thin Solid Films, 1999. 339(1-2): p. 148-153.

29. O'Brien, P., et al., New approaches to chemical bath deposition of chalcogenides. Chemical Processing of Dielectrics, Insulators and Electronic Ceramics, 2000. 606: p. 199-204.

30. Bayer, A., D.S. Boyle, and P. O'Brien, In situ kinetic studies of the chemical bath deposition of zinc sulfide from acidic solutions. Journal of Materials Chemistry, 2002. 12(10): p. 2940-2944.

31. Zhu, Y.P., et al., Sonochemistry-assisted synthesis and optical properties of mesoporous ZnS nanomaterials. Journal of Materials Chemistry A, 2014. 2(4): p. 1093-1101.

32. Pathak, C.S., M.K. Mandal, and V. Agarwala, Optical properties of undoped and cobalt doped ZnS nanophosphor. Materials Science in Semiconductor Processing, 2013. 16(2): p. 467-471.

33. Wang, C.F., et al., Luminescence properties of ZnS/porous Si composites. Optik, 2014. 125(1): p. 554-556.

34. Akhtar, M.S., et al., Optimising conditions for the growth of nanocrystalline ZnS thin films from acidic chemical baths. Materials Science in Semiconductor Processing, 2015. 30: p. 292-297.

35. Antony, A., et al., The effect of the $\mathrm{pH}$ value on the growth and properties of chemical-bathdeposited ZnS thin films. Materials Chemistry and Physics, 2005. 90(1): p. 106-110.

36. Jung, Y.S., et al., Luminescence of bound excitons in epitaxial ZnO thin films grown by plasmaassisted molecular beam epitaxy. Journal of Applied Physics, 2006. 99(1): p. 013502.

37. Sen, S., S. K. Halder, and S. P. Sen Gupta, An X-Ray Line Broadening Analysis in the VacuumEvaporated Silver Films. Journal of the Physical Society of Japan, 1975. 38(6): p. 1641-1647.

38. Kim, K.S. and N. Winograd, X-Ray Photoelectron Spectroscopic Binding-Energy Shifts Due to Matrix in Alloys and Small Supported Metal Particles. Chemical Physics Letters, 1975. 30(1): p. 91-95.

39. Tec-Yam, S., et al., High quality antireflective ZnS thin films prepared by chemical bath deposition. Materials Chemistry and Physics, 2012. 136(2-3): p. 386-393.

40. Turner, G.L.E., Crc Handbook of Chemistry and Physics - a Ready-Reference Book of Chemical and Physical Data, 70th Edition - Weast, Rc, Lide,Dr. Annals of Science, 1991. 48(5): p. 496-497.

41. Borah, J.P., J. Barman, and K. Sarma, Structural and optical properties of ZnS nanoparticles. Chalcogenide Lett, 2008. 5(9): p. 201-208.

42. Chen, L.Y. and C. Fang, OH- effect on the growth and structural properties of Chemical Bath Deposited ZnS quantum thin films. Mechanical Engineering, Materials and Energy li, 2013. 281: p. 523-526.

43. Shin, S.W., et al., Preparation and characteristics of chemical bath deposited ZnS thin films: Effects of different complexing agents. Journal of Alloys and Compounds, 2012. 526: p. 25-30.

44. Zhang, W., et al., Phase controlled synthesis and optical properties of ZnS thin films by pulsed laser deposition. Materials Research Bulletin, 2013. 48(10): p. 3843-3846.

45. Zhang, W., et al., Synthesis and investigation of blue and green emissions of ZnS ceramics. Journal of Luminescence, 2013. 134(0): p. 498-503.

46. Wageh, S., Z.S. Ling, and X. Xu-Rong, Growth and optical properties of colloidal ZnS nanoparticles. Journal of Crystal Growth, 2003. 255(3-4): p. 332-337.

47. Kumbhojkar, N., et al., Photophysical properties of ZnS nanoclusters. Journal of Applied Physics, 2000. 88(11): p. 6260-6264. 
48. Chae, W.-S., et al., Ultraviolet emission of ZnS nanoparticles confined within a functionalized mesoporous host. The Journal of Physical Chemistry B, 2004. 108(31): p. 11509-11513.

49. Yang, J., et al., Mesoporous zinc-blende ZnS nanoparticles: synthesis, characterization and superior photocatalytic properties. Nanotechnology, 2008. 19(25): p. 255603.

50. An, D., et al., Synthesis of porous ZnO structure for gas sensor and photocatalytic applications. Colloids and Surfaces A: Physicochemical and Engineering Aspects, 2014. 447: p. 81-87. 